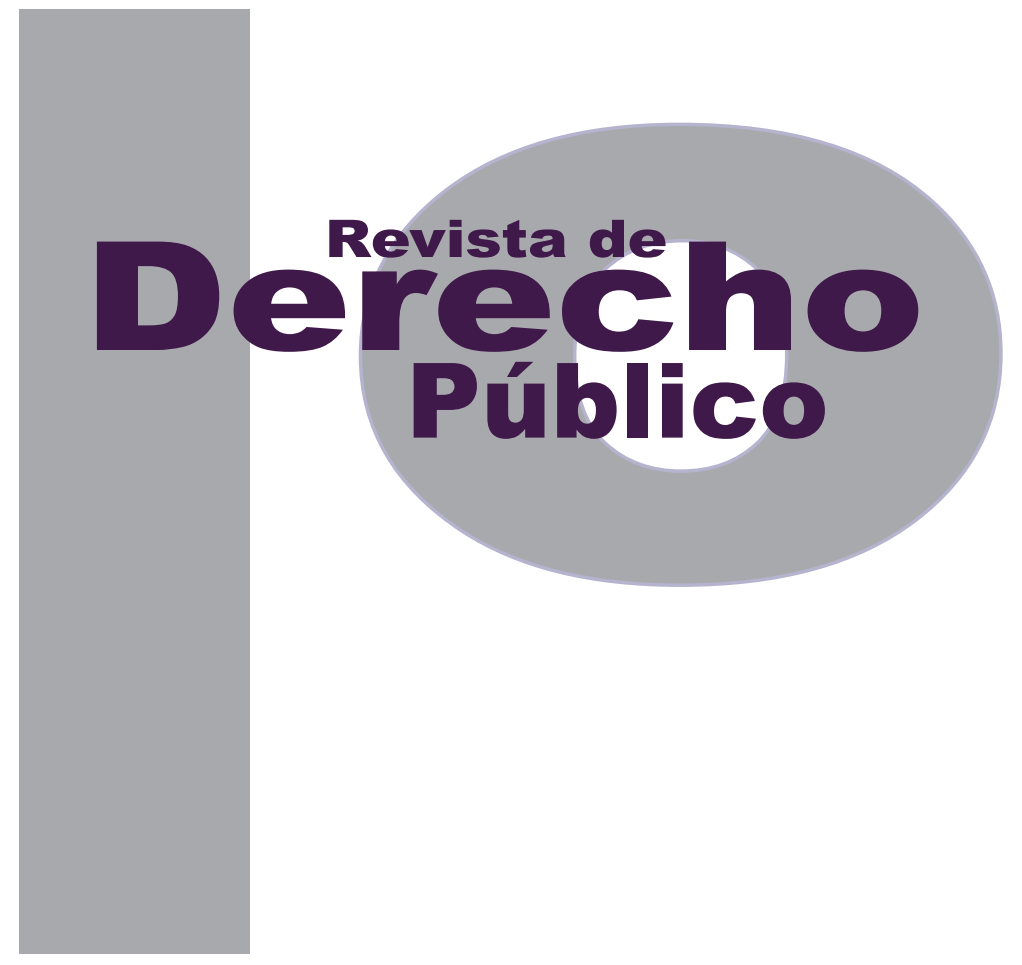

\title{
LAS PSICOPATOLOGÍAS QUE SE RELACIONAN CON LA VIOLENCIA INTRAFAMILIAR: INVESTIGACIONES DESARROLLADAS EN COLOMBIA
}

\author{
Daniela Sánchez CaRdozo \\ Revisión de tema \\ DOI: http://dx.doi.org/10.15425/redepub.33.2014.28 \\ Universidad de los Andes \\ Facultad de Derecho \\ Revista de Derecho Público N. ${ }^{\circ} 33$ \\ Julio - Diciembre de 2014. ISSN 1909-7778
}




\section{Las psicopatologías que se relacionan con la violencia intrafamiliar: investigaciones desarrolladas en Colombia}

\section{Resumen}

Este artículo tiene como propósito acercarnos al estado del arte en materia de investigaciones realizadas en Colombia sobre trastornos mentales y psicológicos en relación con la violencia intrafamiliar. Para cumplir con el objetivo trazado se realizó una búsqueda extensa en revistas médicas, bases de datos de bibliotecas de universidades alrededor del país, documentos producidos por organismos gubernamentales y buscadores de Internet. De la investigación llevada a cabo se encontró que varios estudios adelantados en el territorio nacional se limitan a hacer una recopilación teórica del desarrollo del tema a nivel internacional y que los esfuerzos empíricos para analizar la problemática colombiana han sido pocos para poder extraer conclusiones significativas de la población nacional.

Palabras clave: violencia intrafamiliar, psicopatologías, trastornos mentales, maltrato infantil, estado del arte.

\section{The psychopathologies associated to domestic violence: Research performed in Colombia}

\section{Abstract}

This article aims to make a "state of the art" of all the investigations conducted or centered in Colombia as a case of study regarding the mental and psychological disorders in relation to domestic violence. To meet the goal set, medical journals, databases, libraries around the country, documents produced by government agencies and websites were consulted. From the research conducted it was found that several studies are limited to make a compilation of the theoretical international development on the subject. Meanwhile, the empirical efforts to analyze Colombia's problems have been few; therefore meaningless conclusions can be drawn from the national population.

Keywords: domestic violence, psychopathology, mental disorders, child abuse, state of the art.

\section{As psicopatologias que se relacionam com a violência intrafamiliar: investigações desenvolvidas na Colômbia}

\section{Resumo}

Este artigo tem como propósito acercar-nos ao estado da arte em matéria de investigações realizadas na Colômbia sobre transtornos mentais e psicológicos em relação com a violência intrafamiliar. Para cumprir com o objetivo traçado foi realizada uma busca extensa em revistas médicas, bases de dados de bibliotecas de universidades ao redor do país, documentos produzidos por organismos governamentais e buscadores de internet. Da investigação realizada se encontrou que vários estudos feitos no território nacional se limitam a fazer uma recopilação teórica do desenvolvimento do tema a nível internacional e que os esforços empíricos para analisar a problemática colombiana têm sido poucos para poder extrair conclusões significativas da população nacional.

Palavras-chave: violência intrafamiliar, psicopatologias, transtornos mentais, maltrato infantil, estado da arte. 


\title{
Las psicopatologías que se relacionan con la violencia intrafamiliar: investigaciones desarrolladas en Colombia*
}

\author{
Daniela Sánchez Cardozo**
}

\begin{abstract}
SUMARIO
Ilntroducción - A. Análisis de las fuentes encontradas - B. Análisis del contenido de las investigaciones estudiadas - I. TRASTORNOS RELACIONADOS CON LA VIOLENCIA EN LA PAREJA - A. Trastornos asociados al hombre maltratador - $B$. Trastornos asociados a las mujeres víctimas del maltrato - II. TRASTORNOS ASOCIADOS AL MALTRATO INFANTIL - A. Trastornos relacionados con los padres y madres que ejercen maltrato sobre sus hijos - 1. Investigaciones que se limitan a enunciar los trastornos asociados con el maltrato infantil ejercido por los padres y madres - 2. Investigaciones que utilizan métodos de recolección de datos para establecer los trastornos asociados con el maltrato infantil ejercido por los padres - B. Trastornos relacionados con los niños víctimas de maltrato infantil - 1. Estudios teóricos sobre los trastornos asociados al maltrato infantil - 2. Estudios cualitativos y cuantitativos de los trastornos asociados al maltrato infantil - III. LA RESILIENCIA COMO MECANISMO DE SUPERACIÓN DEL TRAUMA - IV. DISCUSIÓN - V. CONCLUCIONES Referencias.
\end{abstract}

Cómo citar este artículo: Sánchez, J. M. (Diciembre, 2014). Las psicopatologías que se relacionan con la violencia intrafamiliar: investigaciones desarrolladas en Colombia. Revista de Derecho Público, 33. Universidad de los Andes (Colombia).

** Abogada de la Universidad de los Andes y estudiante de la Especialización en Tributación de la misma Universidad. Actualmente trabaja en el equipo de impuestos de la firma Brigard \& Urrutia Abogados S.A.S. 
Introducción

La violencia intrafamiliar (VIF) es un fenómeno complejo que debe ser estudiado desde distintos ejes para poder ser comprendido a cabalidad. Como consecuencia de los altos índices de violencia en Colombia, es necesario contar con un conocimiento amplio sobre esta problemática para enfrentarla de forma eficiente y eficaz. De esta manera se podrán construir mejores políticas públicas que respondan a las particularidades de la violencia doméstica en el país. En consecuencia, para realizar un estudio jurídico completo del tema es necesario estudiar la VIF desde otras ciencias y enfoques. Por esta razón surge la necesidad de realizar una búsqueda sobre lo que se ha investigado en otras áreas del conocimiento.

Una de las formas de abordar el estudio de la viF es indagar las causas de las que esta se deriva o aquellas que la potencializan, y los efectos que produce sobre los miembros de la familia afectada. Los trastornos mentales y psicosociales han sido considerados como una de las posibles causas o efectos en estas relaciones.
Para empezar, esta primera parte tiene como propósito conocer el estado del arte de las investigaciones realizadas en Colombia y sobre el caso colombiano, en materia de trastornos mentales y psicológicos en relación con la VIF. De esta manera, al sintetizar la información se podrá realizar una clasificación sobre las fuentes y el número de investigaciones existentes, los conocimientos obtenidos en estas, su relevancia, impacto y suficiencia, para luego profundizar desde una perspectiva nacional, en la relación de los trastornos con la viF y poder concluir si existen relaciones de causalidad entre estos o si, por el contrario, son una mera coincidencia.

Para cumplir con el objetivo trazado se realizó una búsqueda de investigaciones que estudian la VIF desde una perspectiva psicológica en Colombia, o que tuvieran a este país como centro de su análisis. Para ello se utilizaron descriptores y se consultaron las siguientes fuentes: revistas médicas, bases de datos de bibliotecas de universidades alrededor del país, documentos producidos por organismos gubernamentales y buscadores de Internet. La información se resume en el cuadro 1. 


\begin{tabular}{|c|c|c|c|}
\hline Fuente general & Fuente particular & Descriptores utilizados & $\begin{array}{l}\text { Número de } \\
\text { documentos } \\
\text { encontrados }\end{array}$ \\
\hline $\begin{array}{l}\text { Revistas médi- } \\
\text { cas en línea }\end{array}$ & $\begin{array}{l}\text { PubMed; Lilacs; Scielo; Ovid; Pro- } \\
\text { Quest; Ebsco; Redalyc; Endunexos; } \\
\text { Revista Colombiana de Psicología; } \\
\text { Revista Latinoamericana de Psi- } \\
\text { cología; Revista Médica; Revista } \\
\text { Nacional de Salud Pública; Revista } \\
\text { Psicología Científica; Revista In- } \\
\text { fancia, Adolescencia y Familia; Re- } \\
\text { vista Colombiana de Obstetricia y } \\
\text { Ginecología; y Revista Biomédica. }\end{array}$ & $\begin{array}{l}\text { Violencia intrafamiliar, psicología de la vio- } \\
\text { lencia intrafamiliar, trastornos mentales aso- } \\
\text { ciados a la violencia intrafamiliar, trastornos } \\
\text { mentales + violencia intrafamiliar, psicopatolo- } \\
\text { gías asociadas a la violencia intrafamiliar, tras- } \\
\text { tornos niños víctimas violencia intrafamiliar } \\
\text { Colombia, trastornos déficit de atención mal- } \\
\text { trato infantil Colombia, trastornos psicológicos } \\
\text { niños maltrato infantil, estrés postraumático + } \\
\text { violencia intrafamiliar. }\end{array}$ & 21 \\
\hline $\begin{array}{l}\text { Buscadores de } \\
\text { Internet }\end{array}$ & Google y Google Académico & $\begin{array}{l}\text { Violencia intrafamiliar, psicología de la vio- } \\
\text { lencia intrafamiliar, trastornos mentales aso- } \\
\text { ciados a la violencia intrafamiliar, trastornos } \\
\text { mentales + violencia intrafamiliar, psicopatolo- } \\
\text { gías asociadas a la violencia intrafamiliar, tras- } \\
\text { tornos niños víctimas violencia intrafamiliar } \\
\text { Colombia, trastornos déficit de atención mal- } \\
\text { trato infantil Colombia, trastornos psicológicos } \\
\text { niños maltrato infantil, estrés postraumático + } \\
\text { violencia intrafamiliar. }\end{array}$ & 28 \\
\hline $\begin{array}{l}\text { Bibliotecas } \\
\text { virtuales de } \\
\text { distintas univer- } \\
\text { sidades }\end{array}$ & $\begin{array}{l}\text { Base de datos de la biblioteca vir- } \\
\text { tual de la Universidad del Rosario, } \\
\text { Universidad de los Andes, Univer- } \\
\text { sidad de la Sabana, Universidad } \\
\text { Externado, Universidad Nacional } \\
\text { (todas sus sedes), Pontificia Uni- } \\
\text { versidad Javeriana, Universidad } \\
\text { del Cauca, Universidad Católica y } \\
\text { Universidad del Norte. }\end{array}$ & $\begin{array}{l}\text { Violencia intrafamiliar, psicología de la vio- } \\
\text { lencia intrafamiliar, trastornos mentales aso- } \\
\text { ciados a la violencia intrafamiliar, trastornos } \\
\text { mentales + violencia intrafamiliar, psicopatolo- } \\
\text { gías asociadas a la violencia intrafamiliar, tras- } \\
\text { tornos niños víctimas violencia intrafamiliar } \\
\text { Colombia, trastornos déficit de atención mal- } \\
\text { trato infantil Colombia, trastornos psicológicos } \\
\text { niños maltrato infantil, estrés postraumático + } \\
\text { violencia intrafamiliar. }\end{array}$ & 17 \\
\hline $\begin{array}{l}\text { Instituciones } \\
\text { gubernamen- } \\
\text { tales }\end{array}$ & $\begin{array}{l}\text { Ministerio de Salud, Defensoría } \\
\text { del Pueblo, Procuraduría, Instituto } \\
\text { Colombiano de Bienestar Familiar } \\
\text { y alcaldías. }\end{array}$ & $\begin{array}{l}\text { Violencia intrafamiliar, psicología de la violen- } \\
\text { cia intrafamiliar, trastornos mentales asocia- } \\
\text { dos a la violencia intrafamiliar. }\end{array}$ & 3 \\
\hline
\end{tabular}

El artículo está estructurado en tres partes: en la primera se presentará un análisis de las fuentes encontradas; en la segunda se realizará una descripción de las conclusiones a las que se llegó en las investigaciones en Colombia, para lo cual se estudiarán los trastornos psicosociales asociados a la violencia en la pareja, los relacionados con el maltrato infantil y se expondrá el fenómeno de la resiliencia; posteriormente se adelantará una discusión sobre los resultados obtenidos; y por último, se presentarán algunas conclusiones. 


\section{A. Análisis de las fuentes encontradas}

En la presente sección se expondrán los datos obtenidos en la investigación, para lo cual, primero, se presentarán el número y clase de fuentes encontradas; segundo, se analizarán el número de autores involucrados en cada investigación; luego se indagará si se ha estudiado en mayor medida el maltrato infantil o la violencia en la pareja; y por último, el tipo de artículos que se han publicado en esta materia.

Usando los descriptores antes relacionados se encontraron un total de 43 fuentes relevantes para la investigación, dentro de las cuales están libros, tesis de grado publicadas en las bases de datos de las respectivas universidades, investigaciones y tesis publicadas en revistas electrónicas (en su mayoría médicas), memorias de congresos, investigaciones de grupos universitarios y documentos elaborados por instituciones privadas y públicas. Del total de investigaciones encontradas, 24 estuvieron a cargo de alguna universidad y de estas, 14 fueron realizadas por facultades de Psicología y Enfermería. Adicionalmente, es importante mencionar que, geográficamente, las regiones en las que se estudió esta materia fueron: Antioquia, el Valle y la costa Atlántica colombiana. Los resultados descritos se muestran en las gráficas que se presentan a continuación.

\section{Gráfico 1. Clases de fuentes encontradas}

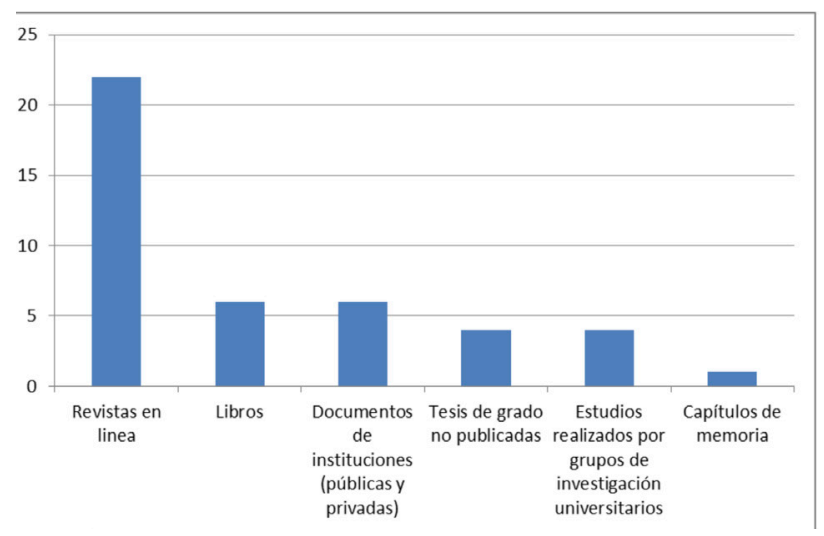

Gráfica 2. Número de investigaciones universitarias

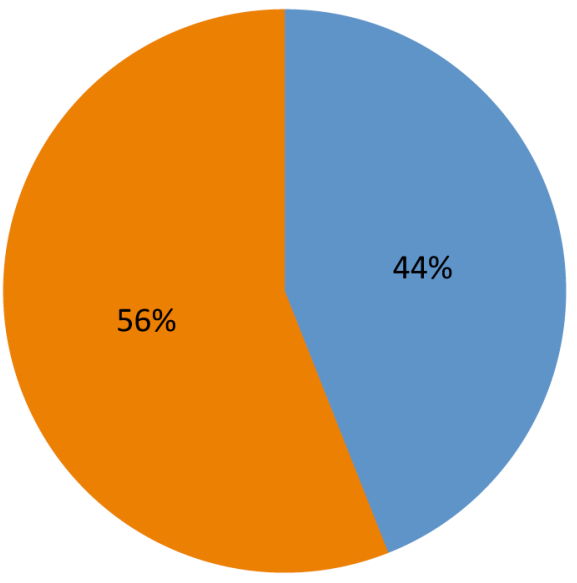

Otras Investigaciones universitarias

Gráfica 3. Facultades que han investigado el tema

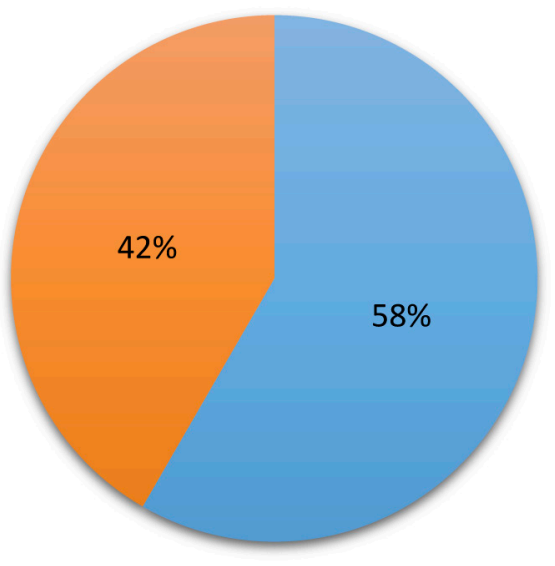

Eacult. Psicol/Enferm. = Otra 
Otra de las variables de análisis tenidas en cuenta al estudiar la información recolectada fue el número de autores institucionales involucrados en la investigación. Se encontró que 33 de las investigaciones fueron realizadas por dos o más autores y las restantes por un solo autor. En consecuencia, 10 investigaciones fueron realizadas por una sola persona. Esto se debe posiblemente al grado de dificultad para obtener y analizar la información. La gráfica 4 muestra estos resultados.

\section{Gráfica 4. Autores institucionales en cada investigación}

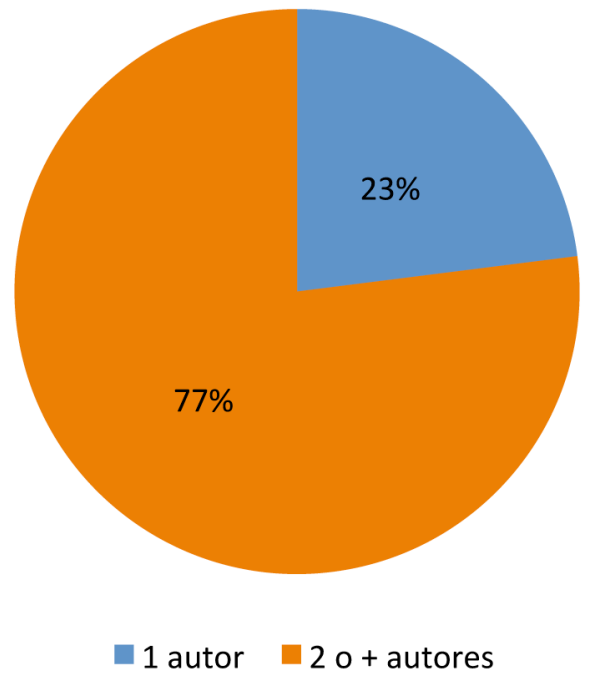

Respecto del tema, es decir, si se investigó sobre maltrato o violencia en la pareja en relación con los trastornos, es posible afirmar que existe cierta equivalencia entre el número de estudios realizados sobre maltrato infantil $(57,14 \%)$ y violencia en la pareja (42,89\%). Solo uno de los estudios integró los dos ejes de investigación. Es consecuencia, en Colombia no existe una tendencia marcada en cuanto a estudiar una problemática más que la otra. La gráfica 5 presenta la información descrita.
Gráfica 5. Tema de investigación

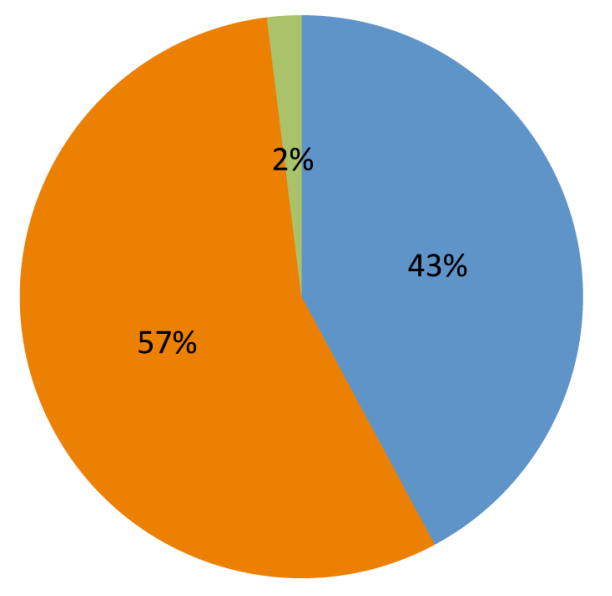

Violencia en pareja Maltrato infantil Ambos

Con los datos encontrados es posible establecer si los estudios realizados son descriptivos o empíricos. Los resultados muestran que se han realizado 22 estudios nacionales descriptivos, correspondientes a investigaciones que se centran en describir y enunciar los posibles trastornos que se asocian con la VIF o en hacer un recuento de bibliografía (principalmente extranjera) sobre el tema. El resto de investigaciones (21) procuran realizar un trabajo de recolección de información en el territorio nacional y analizar los datos de forma cuantitativa o cualitativa. La gráfica 6 resume esta información.

\section{Gráfica 6. Tipo de estudios realizados}

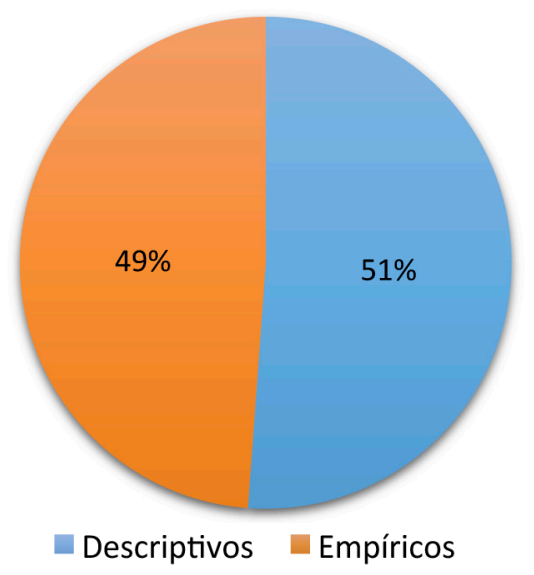




\section{B. Análisis del contenido de las investigaciones estudiadas}

La violencia al interior de las familias se puede presentar entre todos o algunos miembros del núcleo familiar. Dependiendo de la estructura de la familia se dará en la pareja, de padres a hijos, entre hermanos, o entre otras personas como tíos, abuelos, etc. (Defensoría del Pueblo, 2001). El presente estudio tomará como base de análisis la violencia que se presenta entre la pareja y respecto de los padres a los hijos, por ser los tipos de violencia mayormente denunciados. ${ }^{1} \mathrm{~A}$ partir de estas dos clasificaciones se analizarán los trastornos psicológicos que pueden estar asociados a cada manifestación de violencia.

\section{TRASTORNOS RELACIONADOS CON LA VIOLENCIA EN LA PAREJA}

En la siguiente sección se describirán algunas de las conclusiones a las que llegaron los estudios encontrados. Primero se enunciarán los trastornos asociados a los hombres victimarios y posteriormente se estudiarán los relacionados con la mujer víctima. Aunque es claro que también puede haber mujeres victimarias y hombres víctimas, en los estudios analizados en la gran mayoría de los casos el victimario es el hombre y la mujer es la víctima.

1 “De los casos de violencia intrafamiliar, el maltrato conyugal es el más frecuente. Este tipo de maltrato representó en los últimos tres años entre el $56 \%$ y el $57 \%$ de las denuncias. El $93 \%$ de las víctimas fueron mujeres. Por su parte, la violencia contra los menores, incluyendo la agresión psicológica, se presenta en el $50 \%$ de los hogares de manera simultánea a otras formas físicas de violencia y negligencia, que prevalecen en el 15\% de los hogares". (Profamilia, 2010a).

\section{A. Trastornos asociados al hombre maltratador}

Es importante precisar que algunos autores consideran que quienes ejercen o padecen la violencia no tienen un único perfil, es decir, no se ajustan a un patrón psicológico único; ${ }^{2}$ otros estudios sí identifican relaciones entre los victimarios como se verá en líneas posteriores. En el trabajo Características psicológicas de los hombres que ejercen violencia conyugal, un estudio en Bogotá D. C., de Páez, Fonseca y Puche (2002), así como en los de Flórez (2004) y Velásquez y Ospina (2007) se identificaron dos trastornos psicológicos de hombres que ejercen comportamientos violentos hacia su cónyuge. El primero, los trastornos de personalidad, los cuales

consisten en un patrón permanente e inflexible de experiencia interna y de experiencia de la persona, que se aleja demasiado de lo que la cultura en que está inmersa, espera. Se inicia en la adolescencia o principio de la edad adulta, no varía con el tiempo, y causa malestar en el sujeto y prejuicios contra él (Asociación Estadounidense de Psicología [APA], 2013).

Las características comunes halladas fueron la hostilidad, reflejada a través de un alto nivel de comportamientos agresivos o pasivo-agresivos, dependencia afectiva, celos excesivo-compulsivos, síntomas depresivos, personalidad antisocial, baja autoestima, y por último la evasión de las consecuencias emocionales o sentimientos de displacer.

2 Véase Flórez (2004) y Velásquez y Ospina (2007). 
Igualmente, respecto de este mismo tema, el artículo de Velásquez y Ospina (2007), La posición masculina ante la violencia intrafamiliar: una pregunta sobre la afectividad silenciada, determinó que aunque no se puede establecer un perfil característico del hombre maltratador, es posible inferir algunos rasgos de su personalidad, como lo es el "Ideal del Yo social", el cual refleja agresión y competitividad, factores que deben ser trabajados y desmontados en tratamiento terapéutico. Por último, se encontró que no podían hablar de sus problemas y de sí mismos.

El segundo trastorno identificado por el estudio fue el de ansiedad, especialmente el derivado de estrés agudo. Como lo aseguran Browne y Herbert (1997), el estrés es una variable que por sí sola no origina la VIF, pero puede tener influencia en su desencadenamiento, en el nivel de intensidad y en las formas como se materializa la agresión. Para la medición del estrés se usó la escala de apreciación del estrés (EAE), la cual evalúa la presencia de eventos potencialmente estresantes en la vida de una persona y su nivel de intensidad, para así determinar el grado de afectación en el funcionamiento vital.

No obstante, los resultados de este estudio arrojaron que los hombres violentos no presentan niveles de estrés mayores o significativos en comparación con los de hombres no violentos. Esta conclusión va en contravía de la del estudio realizado por Domínguez y Martín (1993), que sí afirma que el estrés es una variable significativa de los hombres maltratadores. Respecto del primer estudio, la escala utilizada es fuertemente criticada por los expertos en el tema, razón por la cual este resultado no es significativo por la falta de consenso y unificación en la escala de medición. ${ }^{3}$

Asimismo, la investigación consignada en el libro Manes, mansitos y manazos: una metodología de trabajo sobre violencia intrafamiliar y sexual (Jimeno et al., 2007), identifica cómo dentro de las causas de la violencia se encuentran los trastornos asociados al consumo de sustancias, esto es, aquellos que se relacionan con drogas de abuso, con los efectos secundarios de medicamentos y con la exposición a sustancias tóxicas (APA, 2013). El abuso de sustancias se presenta por lo menos durante un año, en el que la persona incurre en actitudes como ser incapaz de cumplir con sus obligaciones laborales, educacionales, incurrir en situaciones físicamente riesgosas, etc. (APA, 2013). Adicionalmente, pese a estos problemas no puede detener la injerencia de drogas. Tanto la adicción a sustancias psicoactivas como el síndrome de abstinencia han sido identificados como factores que dan origen al maltrato dentro de las familias. Los trastornos relacionados con el alcohol (Alcaraz y García, s.f.) y la droga (Velásquez y Ospina, 1997) son vistos como los factores más frecuentes que potencializan la respuesta violenta o como detonantes de agresiones. ${ }^{4}$

3 "Un nivel de estrés percibido similar para los dos grupos puede reflejar, en primer término, las dificultades propias de la medición del estrés y el escaso consenso existente en los métodos e instrumentos empleados para la misma, lo cual hace que la comparación de resultados sea problemática" (Velásquez y Ospina, 1997).

4 Sin embargo, no hay un estudio en Colombia que se centre en investigar este fenómeno puntualmente. Aunque el realizado por López, Gómez y Arévalo (2008): Violencia contra la Mujer. Análisis en el Instituto Materno Infantil de Bogotá incluyó la variable en su estudio, no fue el 


\section{B. Trastornos asociados a las mujeres víctimas del maltrato}

Siguiendo con el análisis de los trastornos psicológicos asociados a la mujer como víctima, se encontró que la mayoría de investigaciones buscan analizar cómo los niveles de estrés percibidos, a causa de la violencia, afectan psicológicamente a la mujer maltratada. El estrés es definido como "una transacción entre la persona y el ambiente, que resulta cuando existe una discrepancia real o percibida entre la demanda de la situación y los recursos biológicos, psicológicos o sociales que el individuo interpreta como una amenaza que pone en peligro su bienestar" (Ospina, Jaramillo y Uribe, 2009). Esto lleva a que se supere la capacidad de control del individuo, es decir, que se sobrestimule, y como consecuencia, se agoten sus resistencias fisiológicas y se convierta en distrés. ${ }^{5}$ El trastorno de estrés postraumático se presenta cuando una persona atraviesa un

eje de este. Los resultados arrojados dentro de una muestra de 215 encuestadas indican que el $53,9 \%$ de sus parejas consumen alcohol y el $10,7 \%$ lo hace una vez a la semana. En este mismo sentido, la Encuesta nacional de demografía y salud 2010, realizada por Profamilia (2010a), arrojó que una tercera parte (33\%) de las mujeres manifestó que su esposo o compañero no bebe, el $17 \%$ que su pareja se ha embriagado "muchas veces" durante el año, el 33\% algunas veces y $17 \%$ no se había embriagado durante el último año. Estos datos pueden llevar a concluir que aunque este trastorno puede estar asociado con la violencia, las estadísticas demuestran que no es altamente probable que esté correlacionado con los casos de violencia. Asimismo, de los datos no es posible analizar si es la causa que origina la VIF o es una reacción a esta.

"De hecho, en la Ciencia Psicológica se ha realizado una distinción que divide el estrés en dos grandes tipologías: el distrés y el eustrés. El distrés es el aspecto negativo del estrés, cuando sentimos que no podemos hacerle frente a determinada situación ya que estamos desbordados por sus demandas. Por otra parte, el eustrés sería el estrés positivo, es decir, aquel que nos permite adaptarnos a los cambios y reaccionar rápidamente y con mayor fuerza ante los problemas y peligros que debemos enfrentar (Delgado, s.f.). momento traumático que le causó pavor, impotencia u horror extremo (Ospina et al., 2009) y sus síntomas pueden aparecer meses, incluso años después de los hechos.

Los resultados del estudio Violencia de pareja y salud de las mujeres que consultan a las comisarías de familia en Cali, Colombia, (Canaval, González, Humprheys, De León y González, 2009) demuestran que un alto porcentaje de mujeres que consultan las comisarías por maltrato presentan distrés psicológico, estrés postraumático y trastornos de somatización (histeria crónica). Igualmente, los primeros síntomas que evidencian son depresión e ideación paranoide. Estas variables se corresponden con los resultados obtenidos por Fernández y Fajardo (2002) y con Medición del distrés psicológico de las mujeres maltratadas, Medellín 2003 (Jaramillo, Uribe, Ospina y Cabarcas, 2006a) en los cuales se enfatizó en que las mujeres maltratadas -en comparación con las no maltratadassufren del trastorno de somatización y un alto nivel de neuroticismo, que las lleva a ser más conflictivas en sus relaciones sociales, sentirse inferiores, ser más depresivas y desarrollar trastornos de ansiedad.

En la investigación Estilo de vida, perfil psicológico y demográfico de mujeres maltratadas por su cónyuge (Fernández y Fajardo, 2002) se analizaron los perfiles psicológicos de veinte mujeres maltratadas en la ciudad de Bucaramanga, con el fin de crear un perfil discriminante y evidenciar características comunes relacionadas con trastornos de personalidad. Se encontraron ocho variables que evidencian psicopatologías 
en la personalidad de las mujeres víctimas de violencia. ${ }^{6}$

Por su parte, el artículo de Lasheras y Pires (2003), La violencia contra las mujeres considerada como problema de salud pública: documento de apoyo para la atención a la salud de las mujeres víctimas, demostró que los trastornos cognitivos que afectan a menores y a mujeres se reflejan principalmente en su condición de vulnerabilidad, sentimientos de inseguridad e

6 La primera variable que se encontró fue el alto neurotismo que al combinarla con alta culpabilidad y baja fuerza del yo o inestabilidad emocional, generó la llamada "culpa neurótica". Esta consiste en la necesidad de, por un lado, realizar un cambio trascendental en la forma como se lleva a cabo el proyecto de vida y, por otro, en superar las actitudes que generan afectación. Sin embargo, estos propósitos se ven frustrados por la imposibilidad personal de llevarlos a cabo, produciendo en la persona que lo padece altos niveles de frustración. La segunda, la alta ansiedad, demuestra que las mujeres víctimas de maltrato son crecidamente ansiosas, lo cual puede llevar a generar distintos trastornos. La ansiedad conduce a que sean frustradas e impulsivas, se molesten con facilidad, sean sensibles, tengan problemas de autoimagen, desconfianza, en suma, posean sentimientos disfóricos, pensamientos y sensaciones desagradables. El tercero, la baja fuerza del Yo, significa que al no poder controlarse a sí mismas (no controlar sus sentimientos), tienen poca tolerancia, son inestables emocionalmente y se perturban con facilidad. De esta categoría se deriva la debilidad del yo, la cual se presenta cuando las mujeres maltratadas identifican sus necesidades, pero encuentran difícil hallar alternativas potenciales para satisfacerlas. Situación que se traduce en que cuando deciden un curso de acción para solucionar su situación, no pueden llevarlo a cabo. Estos hechos desencadenan en melancolía, falta de realismo e inestabilidad emocional. La cuarta, el alto control social, demostró que estas mujeres se inclinan por inhibir sus impulsos y orientar su conducta hacia las socialmente convenientes. Su principal interés radica en demostrar una imagen pública respetable y esconden con frecuencia lo que les sucede. La quinta categoría, suspicacia, refleja que son desconfiadas e irritables. La sexta, fuerza del superyó, evidencia la necesidad de mostrarse como emocionalmente estables como mecanismo de defensa, situación que se deriva del contenido ideacional del superyó. La séptima, alta culpabilidad, causa que se sientan inferiores, inseguras, débiles y deprimidas, lo que las hace susceptibles de ser manipuladas. Este factor resultó ser importante porque si se mezclaba con el de suspicacia, derivaba en tendencias suicidas. La octava, la prudencia, es un rasgo de su personalidad, y demostró que el grupo de mujeres maltratadas están caracterizadas por sometimiento, precaución y retraimiento, tienen miedo a cometer errores y son silenciosas e indecisas a la hora de tomar riesgos. Son cautelosas, no solo en su conducta sino también en sus procesos de pensamiento. Finalmente, la sumisión, es un factor que caracteriza la personalidad de la mujer maltratada, porque es obediente, dócil y se convierte en una forma de relacionarse con su pareja para evitar el conflicto (Fernández et al., 2011) indefensión, los cuales se manifiestan en temor, culpa, ansiedad y molestias psicológicas. ${ }^{7}$ Estas conductas son medios de defensa y estrategias de afrontamiento, que tienen como fin minimizar los actos violentos. El problema es que normalmente estos intentos fracasan y prolongan el maltrato por más tiempo.

La investigación Violencia contra la mujer. Análisis en el Instituto Materno Infantil de Bogotá, 2005 (López, Gómez y Arévalo, 2007), pese a que no se centró en analizar el consumo de alcohol y sustancias psicoactivas por mujeres víctimas de violencia, encontró que el $28.8 \%$ de 215 encuestadas consumía alcohol y el 5.5\% lo hacía mínimo una vez al mes, es decir, la mayoría de las encuestadas no lo injería regularmente. En este mismo sentido, la Encuesta nacional de demografía y salud 2010, realizada por Profamilia (2010a), estableció que una cifra importante de las mujeres maltratadas (69\%), manifestó que no bebe, el 1\% reportó que en el año se ha embriagado muchas veces, el $14 \%$ reveló haberlo hecho algunas veces y $16 \%$ confesó que había tomado pero no hasta embriagarse. Los anteriores datos muestran que los trastornos por consumo de sustancias no son una actitud frecuente adoptada por las mujeres maltratadas. Sin embargo, es importante indagar si este hecho es producto o se relaciona con otras variables, como cultura, sociedad, ideologías, forma de enseñanza, etc.

\footnotetext{
7 Mayor información sobre trastorno cognitivo en Pulevasalud: http://www.pulevasalud.com/ps/contenido.jsp?ID=58487\&TIPO_ CONTENIDO=Articulo\&ID_CATEGORIA=2195
} 
En cuanto a los trastornos alimenticios, el estudio de Alarcón, Araújo, Godoy y Vera (2010) reiteró que las alteraciones con la alimentación también pueden ser producto de la violencia ejercida por la pareja. Para afirmar esta hipótesis se examinaron estudios internacionales que analizaron un grupo de personas con desórdenes alimenticios compulsivos. De acuerdo con los autores, estos reportaron dos-tres veces más, mayores índices de abuso sexual o físico. Resultados que también se presentaron en un grupo de mujeres con bulimia nerviosa. Tales datos evidencian que la violencia en el hogar puede desencadenar en trastornos alimenticios. Estos resultados los corrobora el Plan de acción diagnóstico de la violencia intrafamiliar, maltrato infantil y abuso sexual dirigido a niños, niñas y adolescentes y demás integrantes de la familia del municipio de Moniquirá, Boyacá (Alcaldía de Moniquirá, Boyacá, s.f.), el cual establece que dentro de los indicadores conductuales para identificar la violencia, se encuentran enfermedades como la bulimia y la anorexia.

Entre el resto de investigaciones encontradas no se ubicó ninguna otra que analizara otros trastornos derivados o asociados a la viF. Sin embargo, este hecho no implica que otras afecciones psicológicas y mentales puedan estar asociadas como consecuencias o causas del maltrato, por ejemplo, trastornos con nicotina, obsesivo-compulsivos, disociativos, del sueño, entre otros.

\section{TRASTORNOS ASOCIADOS AL MALTRATO INFANTIL}

A continuación se describirán los posibles trastornos que están asociados al maltrato infantil; primero se abordarán los que afectan a los padres como generadores del maltrato, y después los que se relacionan con los menores víctimas de violencia.

\section{A. Trastornos relacionados con los padres y madres que ejercen maltrato sobre sus hijos}

Al analizar las distintas investigaciones halladas es posible clasificarlas en dos grandes grupos: i) las que se limitan a enunciar los trastornos posiblemente relacionados con el maltrato infantil y replican resultados obtenidos en otros estudios y ii) las que usan métodos de recolección de datos y análisis cualitativos o cuantitativos. En las líneas siguientes se analizarán cada una de estas clasificaciones.

\section{Investigaciones que se limitan a enunciar los trastornos asociados con el maltrato infantil ejercido por los padres y madres}

Iniciaremos el listado con el estudio Psicopatología del padre maltratador (Gaviria, 2009), el cual concluyó que en los casos de maltrato se presentan profundos desajustes de personalidad limítrofe y narcisista, coexistiendo con conductas neuróticas y presicóticas, las cuales derivan en personalidades paranoides, situa- 
ción que lleva a la fragmentación del entorno y a generar caos. En algunos casos los defectos de personalidad son estables, pero al combinarse con el consumo de alcohol o de drogas se tornan evidentes.

Los "Padres Problema" 8 son los padres emocionalmente inmaduros cuyas propias necesidades están por encima de todo lo demás; el niño constituye para ellos un reflejo de su propia y no superada inmadurez, lo que conduce a que su inseguridad cause agresiones. También puede ocurrir que estos padres le atribuyen comportamientos adultos a los niños y los culpan como los responsables: "él me odia y por eso crea problemas" (Flórez, 2004). Especialmente los que sufren de personalidad narcisista experimentan una fuerte necesidad de ser admirados y amados, las relaciones interpersonales son superficiales, la empatía escasa, sufren de falta de autocontrol por la debilidad del Yo y son impulsivos. Por ende, es común una adaptación patológica al conflicto, dando lugar a una elevada frecuencia del trastorno psiquiátrico.

En este estudio los trastornos más frecuentes que se hallaron son el de ansiedad, neurosis polisintomática, tendencias sexuales desviadas, estructura de personalidad con características prepsicóticas, impulsos neuróticos, adicción a las drogas o el alcohol y personalidad infantil o inmadura. Resultados similares se presentaron en el artículo Maltrato infantil: un problema multifacético (Gómez, 1998), el cual le atribuyó Este concepto lo desarrolla Flórez (2004) en su investigación para abordar las características comunes de los padres maltratadores. a los padres maltratadores trastornos de personalidad, como inmadurez afectiva, trastornos de autoestima que llevan a que se sientan inseguros frente a sus hijos y usen la violencia como medio de castigo, y trastornos obsesivo-compulsivos y de control impulsos, los cuales los llevan a desarrollar actitudes violentas. Estos datos los corroboran investigaciones realizadas por Klevens et al. (1998), los cuales coinciden con que estos padres presentan baja autoestima, locus de control de tipo externo (tienden a culpar a otros por la ocurrencia de los eventos), inestabilidad emocional, baja tolerancia a la frustración, poco autocontrol, impulsividad, ansiedad, dificultad para establecer vínculos, menos capacidad para establecer empatía, menos asertividad y mayor hostilidad.

Igualmente, la Guía de atención al menor maltratado, realizada por el Ministerio de Salud, estableció que los siguientes trastornos se asocian con el fenómeno del maltrato: i) depresión profunda, ii) alcoholismo y drogadicción, iii) trastornos mentales, iv) antecedentes de maltrato, v) trastornos de ansiedad y vi) somáticos. El estudio El modelo de atención integral a mujeres, niñas y niños víctimas de violencia intrafamiliar llevado a cabo en centros de atención en la ciudad de Barranquilla (Colombia), a su vez determinó que el perfil del agresor depende de los siguientes aspectos: déficit en el control de los impulsos, baja autoestima, déficit en habilidades sociales, victimizado en la infancia, distorsiones cognoscitivas (Romero y Amar, 2009). Por último, el estudio Percepción y sentimientos sobre maltrato infantil en escolares de 9 a 13 años, Institución Educativa Simón Araújo, Escuela del 
Progreso, Sincelejo 2007, de igual forma estableció que los padres y madres agresores son depresivos, irascibles, agresivos, sufren de baja autoestima, deficiente control de impulsos, sufren de estrés y consumen alcohol y drogas (Barragán, Garay, Madera, Méndez y Ucrós, 2007).

\section{Investigaciones que utilizan métodos de recolección de datos para establecer los trastornos asociados con el maltrato infantil ejercido por los padres}

El siguiente conjunto de publicaciones ha realizado mayor investigación en cuanto a la relación de los trastornos y la violencia intrafamiliar en Colombia, especialmente desde la perspectiva del trastorno de consumo de sustancias. En Bogotá, en el 36\% de los casos en los que se presenta maltrato se encuentran presentes antecedentes de alcoholismo o consumo de sustancias (Duque, Caicedo y Sierra, 2008). La investigación Factores cognitivos de los padres, asociados con la co-ocurrencia del consumo de alcohol y el maltrato físico a los hijos (Hewitt, 2005), analizó 43 casos de maltrato en el Hospital de la Universidad del Valle, y encontró que en el $54.8 \%$ de estos, los padres tenían historia de alcoholismo, consumo de marihuana, neurosis o psicosis. Así mismo, de enero a julio de 1992, de 36 casos en el Hospital Infantil Club Noel de Cali, se identificaron $2.2 \%$ de casos de padres que padecían de trastornos (Gaviria, 2009).

Los padres que presentan alteraciones psicológicas relacionadas con sustancias generan comportamientos de defensa maniaca, los cuales Ilevan a que "se genere una inhibición dinámica de la capacidad para pensar acerca del estado mental o emocional del otro e incluso acerca del propio estado mental, creándose así una gran vulnerabilidad al conflicto psíquico" (Gaviria, 2009). La investigación realizada por Hewitt y Rozo (2000) tuvo como propósito analizar la relación entre el consumo de sustancias psicoactivas de los padres y la presencia de maltrato infantil en niños que se encontraban en hogares de protección. Utilizaron una muestra de 213 menores, maltratados y no maltratados, e hijos de padres adictos al alcohol, marihuana, bazuco, cocaína e inhalantes. Los datos arrojados establecieron que la sustancia que más consumen los progenitores abusadores es alcohol, seguido por la marihuana, bazuco, combinación de drogas con alcohol, inhalantes y en último lugar cocaína. El tipo de maltrato proveniente de estos padres es físico, seguido por el verbal y psicológico.

Nohelia Hewitt (2005) por su parte, se centró en determinar cuál es la relación temporal entre el consumo de sustancias y el maltrato, para analizar su co-ocurrencia. Este estudio concluyó que no existe una consecuencia concurrente, consecuente y circular entre estas variables en la mayoría de los casos. Es decir, de la muestra, una población correspondiente al $82 \%$ de los padres adictos y maltratadores presenta los comportamientos de manera independiente. Esto implica que no hay una relación temporal cuando se presenta el maltrato y se consume alcohol, no se daban al tiempo ni son antecedentes dentro de dos horas (tiempo que se utilizó para su medición). Este estudio marca una acentuada diferencia respecto a otras investigaciones pues 
no se limita a establecer una relación, sino que busca si existe una causalidad entre las variables del estudio.

\section{B. Trastornos relacionados con los niños víctimas de maltrato infantil}

Una vez explicados los trastornos asociados con los padres maltratadores, se procederá a ahondar en las investigaciones que han estudiado los trastornos que surgen como consecuencia del maltrato a los niños víctimas de VIF. El impacto del maltrato en el desarrollo y salud del menor ha sido reportado por varios estudios, y su nivel de afección normalmente está relacionado con la severidad e intensidad del evento (Muñoz, 2010). Las secuelas psicológicas que deja el maltrato generan un fuerte impacto en la salud de quienes fueron víctimas; se estima que del 34 al 53\% de los pacientes con salud mental tienen algún antecedente de abuso físico o sexual durante la infancia (Alarcón et al., 2010).

El estudio Ideación suicida en adolescentes y prevalencia y factores asociados encontró que el factor más frecuente que se relaciona con antecedentes de maltrato infantil fue el de trastornos psiquiátricos, especialmente los que corresponden al espectro depresivo (Sánchez, Cáceres y Gómez, 2002). A continuación se expondrán, primero, los estudios teóricos que reagrupan información nacional e internacional sobre el tema, y segundo los que realizan un análisis cuantitativo y cualitativo sobre datos recolectados en Colombia.

\section{Estudios teóricos sobre los trastornos asociados al maltrato infantil}

Dentro de las investigaciones que hacen una enunciación o recuento de bibliografía sobre los posibles trastornos asociados al maltrato, se encuentra el estudio Percepción y sentimientos sobre maltrato infantil en escolares de 9 a 13 años, Institución Educativa Simón Araújo, Escuela del Progreso, Sincelejo 2007, el cual estableció que los niños sujetos a maltrato pueden desarrollar: i) trastornos de identidad, los cuales implican que el niño(a) derive una imagen negativa de sí mismo porque su creencia es que por su culpa es que se genera el conflicto; ii) trastornos de autoestima, especialmente el de baja autoestima pues se sienten inferiores e incapaces (Alarcón et al., 2010). Esto causa que puedan verse representados en dos tipos de comportamiento: timidez o intento de llamar la atención. El primero como demostración de la afección de manera pasiva y el segundo de forma activa, según el estudio de Flórez (2004); iii) trastornos de atención y concentración para poder atender instrucciones; iv) trastornos de comportamiento, los cuales se reflejan en conductas hostiles y desafiantes, atentando contra derechos de otras personas; v) trastornos de ansiedad, que se ven reflejados en extrema ansiedad y angustia; vi) depresión, porque el maltrato les causa sentimientos de tristeza profunda, la cual puede materializarse en comportamientos autodestructivos y de automutilación; y vii) síndrome de estrés postraumático.

El artículo Factores de riesgo asociados al maltrato infantil establece que las víctimas de VIF 
pueden padecer trastornos a corto y largo plazo (Bolívar y Convers, 2012). Dentro de estos se pueden presentar los psicosomáticos y trastornos del sueño, que se derivan del miedo que les causa el maltrato, generando falta de sueño, severas pesadillas u otros síntomas. Los alimenticios que producen conductas como dejar de comer y repeler alimentos. Los trastornos de la eliminación que se manifiestan, por ejemplo, en orinar en lugares inadecuados y de manera persistente.

En relación con las psicopatologías del comportamiento, los niños pueden presentar trastornos por abuso de sustancias y disociativos de identidad por comportamiento perturbador. ${ }^{9}$ Desde una perspectiva emocional se presentan trastornos de ansiedad, depresión, baja autoestima y estrés postraumático. En el ámbito sexual, del maltrato se pueden derivar trastornos sexuales y de la identidad sexual que se representan en conocimientos y deseos sexuales que no corresponden a la edad, masturbación compulsiva, exhibicionismo, fobias sexuales, disfunciones sexuales, entre otras. En cuanto al desarrollo, se encuentran los trastornos de desarrollo infantil, generando riesgos en todos los niveles de desarrollo del niño(a), los cuales pueden producir secuelas irreversibles. Finalmente, desde el aspecto social, se presentan trastornos generalizados al desarrollo, como déficit de habilidades sociales, retraimiento social y conductas antisociales. ${ }^{10}$

9 Estos en su mayoría se caracterizan por hiperactividad, depresión que se evidencia en falta de atención y se materializa en bajo rendimiento escolar, mutilación e incluso suicidio.

10 De igual forma, los artículos de Muñoz Rodríguez y Muñoz Saldarriaga resaltaron que los problemas que presentan los niños maltratados
La publicación Maltrato infantil y sus consecuencias a largo plazo identificó las patologías más comunes asociadas con el maltrato Infantil, tomando como base estudios internacionales (Alarcón et al., 2010). Dentro de sus consideraciones determinó que el síndrome de estrés postraumático es el que con más frecuencia se reporta: $40 \%$ y $50 \%$ de las víctimas de abuso sexual sufren de este (Alarcón et al., 2010). Sus síntomas por lo general son ansiedad, dificultad para dormir, conductas de oposición, falla escolar y comportamientos violentos. Asimismo sostienen que del ambiente conflictivo en la infancia se genera riesgo de reproducir conductas agresivas en la adolescencia y la adultez y asocian el maltrato físico con altas tasas de depresión.

En cuanto a las patologías alimenticias, según los autores, no se derivan con frecuencia trastornos relacionados con la alimentación y el peso. Para este análisis, los niños presentan patologías relacionadas con la insatisfacción corporal, depresión y baja autoestima, pero no alimenticias (Alarcón et al., 2010). Sin embargo, el artículo Factores de riesgo asociados al maltrato infantil sí considera que se presentan comúnmente alteraciones psicológicas alimenticias en niños maltratados (Bolívar y Convers, 2010).

En materia de trastornos con sustancias, se hizo alusión a estudios que comprobaban que

son trastornos conductuales, emocionales y sociales. Dentro de estos se señalaron el de estrés postraumático, de atención, del comportamiento, de aprendizaje (en lo relativo a la capacidad de memorización), del habla, de ansiedad, de las habilidades motoras, psicosomáticos, del estado de ánimo y del sueño. Todas estas categorías fueron simplemente enunciadas. 
pacientes adictos al alcohol, drogas y depresivos en su mayoría presentaban una historia de abuso o negligencia durante la infancia (Bolívar y Convers, 2010). Igualmente, se estableció que en relación con los trastornos de personalidad, como lo indican diferentes estudios, los más comunes eran el paranoide y los límites a la personalidad.

\section{Estudios cualitativos y cuantitativos de los trastornos asociados al maltrato infantil}

Dentro de las investigaciones que recolectan y analizan datos en el territorio nacional está la realizada por Ramírez y Pinzón (2005), con financiación del Plan Internacional y respaldo de la Asociación Afecto, la cual estudió desde una aproximación empírica el fenómeno del maltrato en seis comunidades de la Costa Atlántica y el litoral Pacífico colombiano. Los resultados de este trabajo evidenciaron que los niños de la zona presentaban trastornos de aprendizaje, pues exhibían dificultades a la hora de comprender instrucciones para desempeñar una tarea. Asimismo, trastornos de habilidades motoras que exteriorizaron con problemas de motricidad fina y óculo-manual, detectados a partir del análisis de dibujos que elaboraron y que no correspondían al desarrollo de su edad cronológica. Adicionalmente, los niños presentaron problemas de desarrollo, específicamente de comunicación, al usar lenguaje expresivo.

La investigación Efectos del maltrato infantil en la inteligencia emocional y desarrollo del juicio moral en los niños. Estudio cualitativo, aunque no tuvo como objeto de estudio analizar trastornos asociados con el maltrato infantil, sus resultados permiten establecer una posible correlación con algunos (Celedón y Negrete, 2010). La muestra estuvo constituida por 18 niños(as) víctimas que se encontraban en la Fundación Nuestra Señora del Rosario, en Montería. Dentro de los resultados, se encontró que los niños padecen de déficit en las habilidades sociales, puesto que dentro de sus conductas se les dificulta hacer amigos y mantener conversaciones por periodos prolongados. Esto demuestra que los niños pueden presentar trastornos del desarrollo producto de sus dificultades de interacción social. Sin embargo, deja abierto el interrogante sobre si efectivamente esta secuela se relaciona con el maltrato y no con otros factores como se mencionó anteriormente.

El estudio La violencia intrafamiliar y el aprendizaje en la escuela. Un estudio etnográfico en la institución educativa distrital (I.E.D.) San Francisco Javier, se basa en indagar y describir la incidencia de la viF en el aprendizaje de los niños(as), analizando sus comportamientos dentro y fuera del aula y el rendimiento académico de los estudiantes de séptimo grado de la mencionada institución, en la ciudad de Santa Marta (Vega y Reales, 2009). Este estudio arrojó que los niños que experimentaron maltrato se enojaban con facilidad y cambiaban constantemente de ánimo, situación que puede desencadenar en trastornos del estado de ánimo. Algunos estudiantes presentaron dificultades para relacionarse entre iguales, conductas de agresividad y desobediencia. Estas actuaciones pueden ser producto de algún trastorno del desarrollo. 
Adicionalmente, el estudio concluyó que los niños transfieren al ámbito escolar los problemas de la violencia con la que conviven, y "estas experiencias van creando en la mente del niño modelos de relaciones basadas en la idea de que es normal resolver conflictos de esa manera y entonces los replica en la escuela" (Vega y Reales, 2009). También se presenció que los padres, cuando advierten bajo desempeño académico en sus hijos duplican la violencia y recurren al maltrato para solucionar el problema. Este comportamiento crea un círculo vicioso que, además, genera desmotivación frente al estudio y altos niveles de déficit de concentración. "En el aula fue visible la actitud negativa mostrada por estos estudiantes, aun cuando el docente intentaba motivarlos y repetía una y otra vez las instrucciones" (Vega y Reales, 2009).

Desde el análisis de la lectoescritura y el lenguaje, el estudio demostró que la mayor parte de los niños que sufren violencia no dominan la estructura de palabras, alterando el sonido de estas o las letras. Esta situación confirma su falta de atención y concentración. Otro factor importante es lo que llamaron autoconcepto, el cual es generado por los padres o adultos en la familia de acuerdo con la imagen que le atribuyan al niño sobre sí mismo y sus capacidades, y que de ser negativo conlleva que no reconozcan sus talentos y habilidades intelectuales, emocionales, sociales y creativas. El bajo autoconcepto es producto de las relaciones deficientes entre los miembros de las familias y de un proceso intergeneracional.
En suma, en las conclusiones de la investigación se estableció que la VIF y el aprendizaje escolar están íntimamente ligados. Los niños víctimas presentan problemas en sus procesos emocionales y conductuales, en sus relaciones consigo mismos y con sus compañeros y en sus resultados académicos. La necesidad de atención, manifestada en actuaciones de rebeldía y agresión, demuestra que intentan atentar contra sí y su entorno. Además, su atención dispersa, la falta de concentración y seguimiento de instrucciones, revelan los problemas de aprendizaje y dificultades académicas para rendir en varias áreas del conocimiento. Por consiguiente, su desempeño intelectual resultó menor e insuficiente para un niño de su edad.

\section{LA RESILIENCIA COMO MECANISMO DE SUPERACIÓN DEL TRAUMA}

La violencia intrafamiliar en cualquier etapa de la vida de una persona deja secuelas muy difíciles de superar. Distintos autores creen que la posible recuperación está supeditada a la frecuencia e intensidad de violencia que tuvo que padecer la víctima. Sin embargo, hasta en los casos más extremos, algunas personas logran reponerse a tal punto que superan el trauma y este se convierte en un impulso para crecer emocionalmente como personas, en sus relaciones con los demás, económicamente, laboralmente, etc. Este fenómeno de autosuperación ha sido denominado resiliencia y es definido como "la capacidad individual frente a situaciones de grandes adversidades para adaptarse y restau- 
rar el equilibrio en la vida de la persona y evitar el efecto deletéreo potencial del estrés" (Canaval, González y Sánchez, 2007).

Esta superación psicológica del maltrato ha sido objeto de investigación en los últimos años, pues al poder ser comprendida será una herramienta útil para ayudar a superar a las personas que han sido víctimas de vif. A continuación se analizarán los estudios que se han desarrollado sobre resiliencia en mujeres y niños víctimas del maltrato. Estos principalmente intentan comprender bajo qué supuestos las personas resilientes desarrollan las características, actitudes y posturas frente a los sucesos desafortunados para superarlos y crecer.

El estudio Resiliencia, espiritualidad, aflicción y tácticas de resolución de conflictos en mujeres maltratadas basó su investigación en conocer los niveles de resiliencia y espiritualidad de las mujeres víctimas de maltrato y comparar su relación con el distrés, frecuencia, intensidad y severidad de las lesiones ocasionadas por este (Jaramillo, Ospina, Cabarcas y Humpreys, 2009). La muestra del estudio fue de 199 mujeres maltratadas, que reportaron su situación en 11 comisarías de familia de Medellín. El distrés fue medido con la lista de síntomas SCL-90 R (la más utilizada en los estudios sobre este tema), la cual identifica nueve dimensiones de síntomas primarios: somatización, obsesivo-compulsivo, sensibilidad interpersonal, depresión, ansiedad, hostilidad, ansiedad fóbica, ideas paranoides y psicoticismo. Para medir la resiliencia se utilizó la escala de Wagnid \& Young, constituida por 25 ítems. Por último, la frecuencia, intensidad y severidad del maltrato fue medida a través de la escala de tácticas de conflictos de Strauss y Gelles.

Lo que encontró este estudio es que el 15,1\% de las mujeres recibió una combinación de agresiones leves, moderadas, severas y permanentes. Dentro de los tipos de violencia la más utilizada fue la psicológica 98\%. Las agresiones mayores, menores y sexuales constituyeron un $78,8 \%$. Adicionalmente, las agresiones sexuales y mayores presentaron un 39,2\%, un porcentaje significativo. Por último, la violencia sexual fue de $43,2 \%$.

Las mujeres del estudio presentaron altos niveles de distrés y de violencia. De estos datos resulta una relación compleja: el estrés social puede ser causa de VIF y la VIF causa del estrés. Las mujeres que presentaron síndrome de estrés postraumático habían padecido maltrato con más frecuencia y lesiones severas, moderadas y violencia sexual. En cuanto a la resiliencia, espiritualidad y distrés los resultados obtenidos son importantes, ya que la resiliencia contribuye a la reducción de los síntomas que producen distrés. No obstante, en este estudio no se analizaron con mayor profundidad las características resilientes de personalidad con las que cuentan las mujeres maltratadas, es importante indagar más sobre el tema con el fin de explotarlas y fomentar la superación de las mujeres que padecieron maltrato.

La publicación La resiliencia en la promoción de la salud de las mujeres se centra en hacer un análisis teórico sobre la información a nivel 
internacional que se ha desarrollado en torno al concepto de la resiliencia (Ospina, Jaramillo y Uribe, 2005). Esta inicia analizando las distintas teorías que explican el fenómeno, la anglosajona, la europea y la latinoamericana, concluyendo que las tres tienen en común "observar aquellas condiciones que posibilitan a las personas abrirse paso a un desarrollo exitoso, más sano y positivo en medio de la adversidad, para indicar formas de promoción de la resiliencia" (Ospina, et al., 2005). Asimismo, establece después del análisis teórico los criterios que deben tenerse en consideración para promover la resiliencia en el cuidado de las mujeres.

Finalmente, la investigación Factores asociados a la resiliencia en niños en el contexto colombiano se centró en entender de manera más precisa los factores psicosociales, mediante los cuales los niños(as) víctimas de violencia intrafamiliar pueden desarrollar una personalidad resiliente (Amar, Kotliarenko y Llanos, 2003). La muestra fue un total de 31 menores entre 7 y 12 años, de estratos 1 y 2 , víctimas de VIF, seleccionados después de revisar 267 historias clínicas del Instituto Colombiano de Bienestar Familiar, en la ciudad de Barranquilla. Las categorías que guiaron la elaboración de las entrevistas para identificar personalidades resilientes fueron: autovaloración, autorregulación, competencia y habilidades sociales del niño.

Los resultados obtenidos de las entrevistas y análisis de los datos derivaron en las siguientes conclusiones. Primera, los niños resilientes presentan características y factores que los protegen de la adversidad y les permiten un desarro-
Ilo psicosocial positivo, aun cuando hayan vivido situaciones consideradas de alto riesgo. Segunda, los niños consideran que son personas autovaloradas; se sienten felices por tener padres, familia, amigos; sienten respeto por sí mismos; logran aceptación por los demás; se destacan académicamente; son reconocidos por buenas acciones y son capaces de demostrar y recibir afecto sin importar las circunstancias adversas.

En materia de autovaloración, es posible asegurar que están presentes factores internos y externos especiales en cada niño y que los protegen. En relación con los factores externos se encuentran los familiares, sociales y culturales.

Respecto de los internos, los atributos de la personalidad, físicos, etc. La combinación de estos genera una "dinámica interactiva, capaz de promover desarrollo mental relativamente positivo" (Amar et al., 2003). Esto permite que puedan desenvolverse y adaptarse en las situaciones en que son maltratados y en las que requieren ser aceptados.

El estudio considera que los niños resilientes valoran más sus experiencias positivas que las negativas, o las negativas los fortalecen más, pues como existe la posibilidad de volver a ser agredido les resulta más fácil reponerse que permitir ser lastimado. Estos niños desarrollan sorprendentes capacidades de autorregulación ante sucesos de sentimientos de desagrado, de corregir sus debilidades y miedos y superarlos rápidamente. Otra característica es su facilidad para relacionarse y tienen inclinación a las actividades recreativas, las cuales les sirven para canalizar sus emociones. 
Este estudio es al parecer el primero que analiza el concepto de la resiliencia asociado al maltrato infantil en Colombia. Su aporte es importante y muestra la necesidad de seguir analizando este fenómeno para poder explotar o desarrollar características en niños que se les dificulta superar hechos de maltrato. Así se romperá con la trasmisión intergeneracional de este y podrán crearse prevenciones de la violencia en los hogares colombianos hacia futuro.

\section{DISCUSIÓN}

De los datos encontrados es posible realizar dos tipos de discusiones, una relacionada con los datos cuantitativos y otra que verse sobre el contenido de las investigaciones estudiadas. A continuación se comentarán los resultados obtenidos.

Respecto de la primera variable es posible establecer que en Colombia existe un grupo de investigadores, en su mayoría universitarios (56\%), que se han dedicado a analizar el tema, en especial en las facultades de Psicología y Enfermería (42\%). La costa Atlántica, el Valle del Cauca y Antioquia son las zonas en las que más se ha investigado en el país. La mayoría de estos estudios han sido realizados por varios autores $(77 \%)$, posiblemente por la complejidad de los trabajos; generalmente por grupos académicos; y están publicados en revistas electrónicas, dentro de las cuales priman las médicas. Por último, sorprendió que se encontraran tan pocos documentos elaborados por organismos estatales.
En relación con las temáticas, es posible establecer que se ha estudiado en similares proporciones la violencia en la pareja (47\%) y el maltrato infantil (53\%). Es decir, no se ha dado preponderancia a algún tema. Dentro de estas investigaciones se encontraron dos formas de abordar el objeto de estudio: trabajos descriptivos y empíricos.

En los trabajos empíricos se evidenció que las muestras no son significativas para obtener conclusiones válidas sobre las psicopatologías asociadas con la violencia, pues ninguna de estas es mayor a 300 encuestados o entrevistados. Este es el caso del estudio Estilo de vida, perfil psicológico y demográfico de mujeres maltratadas por su cónyuge, en el cual a pesar del esfuerzo por elaborar un perfil de la mujer maltratada, este no puede ser generalizable para las mujeres víctimas en Bucaramanga o el país, pues la muestra fue de 20 personas (Fernández y Fajardo, 2002).

Sumado a lo anterior, en el campo de la psicología existen diferentes métodos para analizar la información que no están mundialmente avalados, esto causa que por la técnica empleada (por ejemplo la escala de medición del trastorno), los estudios revistan un número significativo de críticas y lleven a que los resultados no sean confiables. Ejemplo de esta situación es el estudio La posición masculina ante la violencia intrafamiliar: una pregunta sobre la afectividad silenciada, en el cual por no haber consenso en la escala de medición utilizada, los resultados obtenidos terminaron siendo problemáticos (Velásquez y Ospina, 2007). 
Como se pudo apreciar, la mayoría de estudios que analizan los trastornos abordan su análisis desde una perspectiva general y solo algunos puntualizan en la investigación de trastornos específicos. Esto conlleva que no se obtengan resultados completos o suficientes sobre cada tipo en particular.

En los pocos estudios que se centran en analizar a fondo una variable específica, la mayoría han versado en la medición del estrés, estrés postraumático o el uso de sustancias. Aunque estos trabajos han arrojado información valiosa, se ha descuidado el estudio de otros trastornos sobre los que se cuenta con poca información. En consecuencia, hacen falta estudios que se centren en analizar otros trastornos que no han sido objeto de suficiente atención, por ejemplo Ios trastornos alimenticios. En este mismo sentido, la resiliencia, que es una fuente esencial para superar la VIF ha sido poco estudiada en el país.

Otro inconveniente que se encontró en las investigaciones es que asumen que causalidad y correlación son lo mismo. Sin embargo, existe una explícita diferencia entre estos conceptos. Que dos variables se presenten en un mismo espacio temporal no implica que sean causales. Esta falta de precisión puede llevar a conclusiones erróneas sobre la relación de la VIF con los trastornos.

En cuanto a los estudios descriptivos es importante resaltar que la mayoría enuncian los posibles trastornos que podrían asociarse a la VIF, y sus afirmaciones en ocasiones no cuentan con sustento pues son una simple apreciación del autor. Esto lleva a que se asocien con la vIF trastornos que no necesariamente están relacionados con esta. Por su parte, otros estudios descriptivos hacen un recuento de bibliografía, en su mayoría, de trabajos realizados en el extranjero.

En suma, pese a que se encontró una serie de investigaciones sobre el tema, quedan fuertes vacíos por resolver. La información no es suficiente para establecer conclusiones que sirvan para abordar la VIF desde este enfoque. Se podría establecer que hace falta: i) analizar trastornos que puedan estar asociados con esta problemática y que no se han estudiado y ii) profundizar en los ya estudiados porque los análisis realizados en el país no son significativos hasta el momento.

\section{CONCLUSIONES}

Varios estudios en el territorio nacional se limitan a hacer una recopilación teórica del desarrollo del tema a nivel internacional. Este esfuerzo es importante porque establece el marco teórico de la materia por autores colombianos y lo unifica. Sin embargo, es necesario adelantar más investigaciones empíricas para comprender los trastornos que mayormente se presentan en nuestro contexto, su frecuencia y causalidad con la violencia. Se necesita abordar este estudio analizando los casos de VIF que se presentan en nuestro país y su causalidad con las categorías diagnósticas que se evidencian. De esta manera, se podrán confirmar los resul- 
tados obtenidos en otras latitudes, o se obtendrán nuevas conclusiones producto de nuestro contexto particular.

Los esfuerzos empíricos para analizar la problemática han sido importantes, pero no suficientes para poder extraer conclusiones significativas de la población nacional. Esto se debe a que la mayoría de estudios no son generalizables, producto de las metodologías utilizadas o del tamaño de las muestras.

No basta con mencionar todos los trastornos mentales que pueden estar relacionados con el problema, o establecer una posible correlación entre estos; es necesario puntualizar su estudio para determinar su verdadera causalidad en los hogares colombianos. De esta manera se enriquecerá el estado del arte de la VIF a través de las investigaciones basadas en el escenario nacional y las necesidades de las familias colombianas. Así se podrán adoptar tratamientos fundados en los trastornos y requerimientos particulares de las víctimas colombianas.

\section{Referencias}

Alarcón Forero, L. C., Araújo Reyes, Á. P., Godoy Díaz, A, P. y Vera Rueda, M. E. (2010). Maltrato infantil y sus consecuencias a largo plazo. Recuperado el 30 de agosto de 2012, de MedUNAB: <http://revistas.unab.edu.co/index. php?journal $=$ medunab \&page $=$ article $\& o p=v i$ ewArticle\&path[]=1155>
Alcaldía de Moniquirá. (s.f.). Plan de acción diagnóstico de la violencia intrafamiliar, maltrato infantil y abuso sexual dirigido a niños, niñas y adolescentes y demás integrantes de la familia del municipio de Moniquirá Boyacá. Recuperado el 30 de agosto de 2012, de Alcaldía de Moniquirá - Boyacá: <http://moniquira-boyaca.gov.co/apc-aa fi-

Alcaraz Gómez, F. H. y García Suárez, I. C. (s.f.). Masculinidades y violencias en Colombia. Desestructuración del modo convencional de hacerse hombre. Recuperado el 31 agosto de 2012, de hombresymasculinidades: <http:// www.hombresymasculinidades.com/pdf/ masc-vilencia.pdf>

Amar Amar, J. J., Kotliarenko, M. A. y Llanos AbeIlo, R. (s.f.). Factores asociados a la resiliencia en niños en el contexto colombiano. Recuperado el 31 de agosto de 2012, de Google: http://www.google.com.co/url?sa=t\&rct=j\&q $=\& e s r c=s \&$ source $=$ web $\& c d=1 \& v e d=0 C C A Q F$ jAA\&url=http $\% 3 A \% 2 F \% 2 F r c i e n t i f i c a s . u n i n o r-$ te.edu.co\%2Findex.php\%2Finvestigacion\%2 Farticle\%2Fdownload\%2F1134\%2F710\&ei$=$ aEFBUImwB4La9ATjwoHADw\&usg=AFQjCN GirWX8WqXtat8hY9TM-OuMwLVFtQ

Asociación Estadounidense de Psicología [APA]. (2013). Manual diagnóstico y estadístico de los trastornos mentales (DMS IV). Recuperado el 31 de agosto de 2012 de files.sld. cu: $\quad$ http://files.sld.cu/arteydiscapacidad/ files/2009/07/manual-diagnostico-y-estadistico-de-los-trastornos-mentales.pdf 
Barragán Acuña, G. J., Garay Arroyo, J. L., Madera Villamizar, R. P., Méndez Villa, R. E. y Ucrós Jaraba, E. P. (s.f.). Percepción y sentimientos sobre maltrato infantil en escolares de 9 a 13 años, institución educativa Simón Araújo, Escuela de Progreso, Sincelejo 2007. Recuperado el 30 de agosto de 2012, de bibliotecaunisucre: <http://biblioteca.unisucre.edu.co:8080/dspace/bitstream/123456789/111/1/T362.7665\%20 P428.pdf>

Bolívar Arango, L. M. y Convers Durán, A. M. (Abril de 2012). Factores de riesgo asociados al maltrato infantil. Recuperado el 30 de agosto de 2012, de intellectum.unisabana: <http://intellectum.unisabana.edu.co:8080/ jspui/bitstream/10818/3377/1/laura_maria_bolivar_arango.pdf >

Browne, K; Herbert, M. (1997). Preventing Family Violence. Chichester: John Wiley \& Sons.

Canaval, G., González, M. C., Humprheys, J., De León, N. y González, S. (2009). Violencia de pareja y salud de las mujeres que consultan a las comisarías de familia en Cali, Colombia. Recuperado el 31 de agosto de 2012, de Investigación y Educación en Enfermería: http://aprendeenlinea.udea.edu.co/revistas/index.php/iee/article/viewFile/2825/

Canaval, G., González, M. C. y Sánchez, M. O. (Octubre-Diciembre de 2007). Espiritualidad y resiliencia en mujeres maltratadas que denuncian su situación de violencia en la pareja. Recuperado el 31 de agosto de 2012, de
Colombia Médica: <http://www.bioline.org. br/pdf?rc07078>

Celedón Rivero, J. y Negrete Sáleme, Y. (2009). Efectos del maltrato infantil en la inteligencia emocional y el desarrollo del juicio moral en niños. Estudio cualitativo. Recuperado el 30 de agosto de 2012, de wb.ucc: <http://wb.ucc. edu.co/pensandopsicologia/files/2010/08/ articulo-03-vol5-n8.pdf>

Defensoría del Pueblo. (2001). Mecanismos de protección contra la violencia intrafamiliar. Recuperado el 30 de agosto de 2012, de Defensoría del Pueblo: http://www.defensoria. org.co/red/anexos/publicaciones/violencia_ intrafamiliar.pdf

Delgado, J. (s.f.). Distrés y eustrés: ¿enemigos o aliados? Recuperado el 14 de enero de 2013, de Rincón de la Psicología: <http://www.rinconpsicologia.com/2012/05/distres-y-eustres-enemigos-o-aliados.html>

Domínguez, E. M. y Martín, M. A. (1993). Estudio de la estructura y el funcionamiento de las parejas que presentan agresión física y su capacidad para elaborar estrategias de afrontamiento del estrés. Bogotá: Universidad Santo Tomás de Aquino.

Duque, L., Caicedo, B. y Sierra, C. (Julio-Diciembre de 2008). Sistema de vigilancia epidemiológica para los municipios colombianos. Recuperado el 30 de agosto de 2012, de Scielo: <http:// www.scielo.org.co/scielo.php? pid=S0120386X2008000200010\&script=sci_arttext> 
Fernández Morales, K. y Fajardo Cuartas, J. F. (2002). Estilo de vida, perfil psicológico y demográfico de mujeres maltratadas por su cónyuge. Recuperado el 30 de agosto de 2011, de Revista Psicología Científica: <http://www.psicologiacientifica.com/bv/psicologia-107-1estilo-de-vida-perfil-psicologicoy-demograficode-mujeres-m.html>

Flórez, A. C. (2004). Evaluaciones y atribuciones sobre las conductas infantiles de madres bogotanas con alto y bajo potencial de maltrato físico infantil. Bogotá: Universidad de los Andes. Facultad de Biología.

Gaviria, L. F. (14 de agosto de 2009). Psicopatología del padre maltratador. Recuperado el 30 de agosto de 2012, de Asociación Afecto contra el Maltrato Infantil: <http://www. afecto.org.co/noticias.htm?x=20159953\#_ edn12>

Gómez, S. (1988). Maltrato infantil: un problema multifacético. Recuperado el 30 de agosto de 2012, de redalyc: <http://redalyc.uaemex.mx/redalyc/pdf/805/80520201.pdf>

Hewitt Ramírez, N. (Marzo de 2005). Factores cognitivos de los padres, asociados con la co-ocurrencia del consumo de alcohol y el maltrato físico a los hijos. Recuperado el 30 de agosto de 2012, de Scielo: <http:// www.scielo.org.co/scielo.php?pid=S012391552005000100002\&script=sci_arttext>

Hewitt Ramírez, N. y Rozo, M. (2000). Relación entre el consumo de sustancias psicoactivas de los padres y la presencia de maltrato infantil en los niños ubicados en instituciones de protección. Bogotá: Universidad Católica de Colombia, Facultad de Psicología.

Jaramillo, D. E., Uribe, M. T., Ospina, D. E. y Cabarcas-lglesias, G. (2006a). Medición de distrés psicológico de las mujeres maltratadas, Medellín, 2003. Recuperado el 30 de agosto de 2012, de Scielo: <http:// www.scielo.org.co/scielo.php?pid=S165795342006000200008\&script=sci_arttex>

Jaramillo, D. E., Ospina, D., Uribe, M. T. y Cabarcas-Iglesias, G. (2006b). Escala de identificación de las etapas de cambio conductual en las mujeres en una relación conyugal violenta. Revista Latinoamericana de Psicología, 83(3). Recuperado el 30 de agosto de 2012, de Scielo: <http://www.scielo.unal.edu.co/ scielo.php?script=sci_arttext\&pid=S012005 342006000300006\&lng=es\&nrm= >

Jaramillo, D. E., Ospina, D., Cabarcas-Iglesias, G. y Humpreys, J. (2009). Resiliencia, espiritualidad, aflicción, y tácticas de resolución de conflictos en mujeres maltratadas. Recuperado el 30 de agosto de 2012, de Scielo: http:// www.scielosp.org/pdf/rsap/v7n3/v7n3a04. pdf

Jaramillo, D. E. y Uribe, T. M. (2000). La violencia conyugal en Medellín: un problema de salud que afecta a las mujeres. Recuperado el 30 de agosto de 2012, de Index: <http://www. index-f.com/index-enfermeria/30revista/ r30_articulo_17-21.php> 
Jimeno, M., Góngora, A., Martínez, M., Suárez, C., Rodríguez, M., Rodríguez, C., Castro, L., Caviedes, M., Rincón, F. y Rivera, C. (2007). Manes, mansitos y manazos: una metodología de trabajo sobre violencia intrafamiliar y sexual. Bogotá: Universidad Nacional, Facultad de Ciencias Humanas.

Klevens, J., Ardila, S., Bayón, M. C., Ramírez, C., Sierra, M., Uribe, N. y Vargas, E. (1998). Prevención primaria del maltrato infantil: ensayo controlado de cinco intervenciones. Bogotá: Secretaría Distrital de Salud.

Lasheras Lozano, M. L. y Pires Alca, M. (Mayo de 2003). La violencia contra las mujeres considerada como problema de salud pública: documento de apoyo para la atención a la salud de las mujeres víctimas. Recuperado el 30 de agosto de 2012, de Madrid.org: http://www. madrid.org/cs/Satellite?blobcol=urldata\&bl obheader=application\%2Fpdf\&blobheadern ame1=Content-disposition\&blobheadernam e2=cadena\&blobheadervalue $1=$ filename $\% 3$ Dd086_revisado.pdf\&blobheadervalue2=Ian guage\%3Des\%26site\%3DPortalSalud\&blobk ey=id\&blobtable $=$ MungoBlobs \&blobwhere $=1$ $352861196225 \&$ ssbinary $=$ true

López, M. S., Sánchez Gómez, I. P. y Arévalo Rodríguez, I. (2008). Violencia contra la mujer. Análisis en el Instituto Materno Infantil, Colombia, 2005. Estudio de carácter transversal. Revista Colombiana de Obstetricia y Ginecología, 59(8). Recuperado el 30 de agosto de 2012, de Fecolsog: <http://www.fecolsog.
org/userfiles/file/revista/Revista_Vol59No1_ Enero_Marzo_2008/v59n1a02.pdf >

Ministerio de Salud. (2011). Guía de atención del menor maltratado. Recuperado el 30 de agosto de 2012, de Ministerio de Salud: http://www.minsalud.gov.co/Documentos\%20y\%20Publicaciones/Forms/DispForm.aspx?ID=860

Muñoz Rodríguez, D. I. (2006) El maltrato infantil: un problema de salud pública. Recuperado el 30 de agosto de 2012 de Unicauca: http:// www.facultadsalud.unicauca.edu.co/Revista/PDF\%5C2006\%5C080412200604.pd

Muñoz Saldarriaga, P. A. (2010). Diseño y validación de un protocolo para detección de factores y conductas de riesgo en maltrato infantil en el municipio de Necoclí, Antioquia. Medellín: Universidad de Antioquia, Facultad de Psicología.

Ospina, D., Jaramillo, D. E. y Uribe, T. M. (2005). La resiliencia en la promoción de la salud de las mujeres. Recuperado el 30 de agosto de 2012, de redalyc: http://www.redalyc.org/articulo.oa?id=105215401007

Páez Rodríguez, M.; Fonseca Ávila, A. P.; Puche Navarrete, J. J. Características psicológicas de los hombres que ejercen violencia conyugal, un estudio en Bogotá D. C. Recuperado el 30 de agosto de 2012 de Revista Colombiana de Psicología: http://www.google.com.co/url ?sa $=\mathrm{t} \& \mathrm{rct}=\mathrm{j} \& \mathrm{q}=\& \mathrm{esrc}=\mathrm{s} \&$ source $=$ web $\& \mathrm{~cd}=1$ \&ved=0CCIQFjAA\&url=http $\% 3 A \% 2 F \% 2 F w w w$. 
revistas.unal.edu.co\%2Findex.php\%2Fpsicol ogia\%2Farticle\%2Fdownload\%2F1200\%2F1 751\&ei=8VtBUOyJFI-u8QSin4H4Aw\&usg=AF QjCNGpSXxnooUOLMXm6YUmuBWPsFo3Yg

Profamilia. (2010a). Encuesta nacional de demografía y salud. Obtenido de Profamilia: http://www.profamilia.org.co/encuestas/Profamilia/Profamilia/index.php?option=com_ content\&view=article\&id=63\&ltemid $=7$

Profamilia. (2010b). Capítulo 13. Violencia contra las mujeres y los niños. En Encuesta nacional de demografía y salud. Recuperado el 30 de agosto de 2012, de Profamilia: http:// www.profamilia.org.co/encuestas/Profamilia/Profamilia/index.php?option=com_conte nt\&view=article\&id=146\&ltemid=116

Ramírez, C; Pinzón, A. (2005). Prevalencia y factores asociados al maltrato infantil en seis comunidades de la Costa Atlántica y el Litoral Pacífico. Bogotá: Plan Internacional.

Romero Mendoza, V. M. y Amar Amar, J. (2009). El modelo de atención integral a mujeres, niñas y niños víctimas de violencia intrafamiliar llevado a cabo en centros de atención en la ciudad de Barranquilla (Colombia). Obtenido de google: <http://www.google.com.co/url?s $a=t \& r c t=j \& q=\& e s r c=s \&$ source $=$ web $\& c d=1 \& v$ ed=0CCsQFjAA\&url=http\%3A\%2F\%2Frcientifi cas.uninorte.edu.co\%2Findex.php\%2Finvesti gacion\%2Farticle\%2Fdownload\%2F797\%2F4
50\&ei=50UeUdLOAYna8ASa8ICwDw\&usg=A FQjCNGpjh5v_xug69tswxtOT7sZFxzGaA\&bvm $=$ bv.42553238,d.eWU>

Sánchez, R., Cáceres, H. y Gómez, N. (2002). Ideación suicida en estudiantes universitarios: prevalencia y factores asociados. Recuperado el 30 de agosto de 2012, de Redalyc: <http://redalyc.uaemex.mx/redalyc/ pdf/843/84309609.pdf>.

Trastorno cognitivo. (25 de agosto de 2009). Obtenido de Pulevasalud: http://www.pulevasalud.com/ps/contenido.jsp?ID=58487\&TIPO_ CONTENIDO=Articulo\&ID_CATEGORIA=2195

Vega Lara, L. y Reales Agón, O. (2009). La violencia intrafamiliar y el aprendizaje en la escuela: Un estudio etnográfico en la Institución Educativa Distrital (I.E.D). Recuperado el 30 de agosto de 2012, de monografías: <http:// www.monografias.com/trabajos71/violenciaintrafamiliar-aprendizaje-escuela/violenciaintrafamiliar-aprendizaje-escuela2.shtml>

Velásquez Molina, D. y Ospina Ospina, A. A. (2007). La posición masculina ante la violencia intrafamiliar: una pregunta sobre la afectividad silenciada. Recuperado el 30 de agosto de 2012, de Revista Virtual Universidad Católica del Norte: <http://revistas.unab.edu.co/ index. php?journal=medunab\&page $=$ article $\&$ op=viewArticle \&path[]=1155> 